\title{
The Respective Effects of Being Observed and Sanctioned in Modified Dictator and Ultimatum Games
}

\author{
Agnès Festré $^{1}$ and Pierre Garrouste ${ }^{2}$ \\ ${ }^{1}$ University of Picardie (France) and GREDEG, University of Nice-Sophia Antipolis, UMR $n^{\circ}$ 6227, \\ 250 rue Albert Einstein, 06560 Valbonne Cedex, France \\ ${ }^{2}$ University of Nice-Sophia Antipolis and GREDEG, UMR $n^{\circ}$ 6227, 250 rue Albert Einstein, \\ 06560 Valbonne Cedex, France
}

Correspondence should be addressed to Agnès Festré; festre@gredeg.cnrs.fr

Received 27 November 2012; Accepted 28 January 2013

Academic Editors: I. Shoji and E. Silva

Copyright (C) 2013 A. Festré and P. Garrouste. This is an open access article distributed under the Creative Commons Attribution License, which permits unrestricted use, distribution, and reproduction in any medium, provided the original work is properly cited.

We experiment within a laboratory the respective effects of being observed and sanctioned in both a dictator and an ultimatum game. We obtain the classical results that individuals do not play the subgame perfect equilibria. We also show that being observed increases the offers made by the proposer in the dictator game but this effect is difficult to identify in the ultimatum game. We also find that in the dictator game, the more the individuals are sensitive to observation the less they are to sanction.

\section{Introduction}

A common result from the recent literature showing that individuals do follow social norms is that sanctions are effective tools to help enforce social norms (This is the case in dictator games [1], ultimatum games [2,3], prisoner dilemma games [1], or public goods games $[4,5]$. Similar results are found in third-party sanction experiments ([6-8] for an evolutionary game theoretical interpretation.) Some experiments show however that such an assumption can be falsified. According to Fehr and Schmidt [9], agents' efforts are lower when principals condition a fine on the deviation from a desired effort level. Fehr and Gächter [10] or Fehr and List [11] not only show that positive incentives can crowd out motivations but also that sanctions may undermine agents' motivations.) What is however less appreciated in the economic literature is that individuals not only anticipate the sanction and its level, but also modify their behavior when others are watching them. Lewitt and Levin [12] show for instance that depending on the level of scrutiny that results from the fact that "people are aware that their behavior is being monitored, recorded, and subsequently scrutinized" [12, page 59]), individuals may behave differently in laboratory and field experiments. They suggest that scrutiny in lab experiment leads to overestimate the importance of prosocial behaviors relative to environments without such scrutiny due to an "artificially" induced moral/social cost in labs. However, they mainly refer to scrutiny as emanating from the experimenter. By contrast, we test whether being observed by a third party affects individuals' decisions and compare this effect with the sanction effect. This attempt is of both theoretical and empirical interest. From the theoretical viewpoint, it permits to disentangle the sanction effect from the scrutiny effect, in contrast to experiments such as public good games with sanctions in which the two effects are usually blended. Moreover, it addresses the controversial issue of whether fairness is inspired by regard for others (fairness is an intrinsic feature of human beings) or whether it results from external forces, for example, regard by others. A growing literature is now investigating this question in dictator game settings (see for a survey [13]).

From the empirical viewpoint, our attempt suggests that a comparative cost-benefit analysis of the scrutiny versus sanction effect could provide useful information for deciding whether it is more efficient to rely on both rather than on the more important of the two effects only.

In order to test this intuition, we provide experiments that not only show, as in Fehr and Fischbacher [1], that 
(1) a third party (the observer of the game) or a second party (the recipient or the responder) does sanction a first party (the proposer) when his/her offer is deemed to be unfair, but also that (2) the proposer is likely to modify his/her offer when a third party is simply informed about the amount of the offer. We use a within design (and a control experiment), that is, a sequence of dictator (DG) and ultimatum (UG) games between randomly selected pairs of proposer/recipient and introduce at a certain step the fact that a third party is first informed about the transfer from the proposer to the recipient of the pair he is assigned to, and thereafter has the option to sanction (at no cost but under some restricted conditions, see below) unfair offers by deducting a certain amount from the proposer's remaining share. We also ran a control treatment in order to control for learning effects (see below).

Our results show that the relative effects of observation and sanction strongly depend on the institutional setting. In the DG, regard by others has a dramatic effect on the level of the offers, whereas in the UG this effect is difficult to corroborate. In the DG, we observe a negative relationship between the observation effect and the sanction effect. In the UG, the relative effect of observation versus sanction is more ambiguous, since it is hard to disentangle the effects of observation and sanction from competing effects derived from risk aversion attributes of proposers and receivers on one hand, and from expectations by proposers of the level of acceptation (or refusal) of receivers on the other hand. In a nutshell, the fact that the proposer can be sanctioned by both the receiver and the observer makes it difficult to discriminate between the relative effects of those two types of sanction. Consequently, more specific research needs to be done in order to disentangle the observation/sanction effect from the risk aversion/expectation effect.

Related literature concerns the effect of observation by the experimenter or the recipient in dictator and ultimatum games and its various interpretations following the seminal paper by Hoffman et al. [14]. In this paper, Hoffman et al. provide a DG experiment that ensures experimenter-subject anonymity (double-blind treatment) and shows that dictators tend to give more when observed by the experimenter, hence suggesting that "fairness" might not be "own' preference, but a derivative of judgment by others." [14, page 349].

Dana et al. [15] confirm this intuition by introducing a costly exit option to a DG. They show that one-third of participants are willing to exit in a public game but not in another study where the game is private, concluding that giving often reflects a desire not to violate other's expectations rather than a concern for others' welfare per se. Similarly, Andreoni and Bernheim [16] develop a theory that accounts for dictator giving on the basis of the assumption that "people like to be perceived as fair" [16, page 1608].

At the opposite, Bolton and Zwick [17] and Bolton et al. [18] find no significant experimenter anonymity effect. Bolton and Zwick [17] run experiments where they compare three games: a UG, an "impunity game" with full observation by the experimenter for both and a "zero knowledge game" (UG without experimenter observation). They find that although the "impunity game" and DGs are very similar in their design, dictators in the "impunity game" demonstrate an unwillingness to leave anymore than the minimum, regardless of the minimum which is $5 \%$ or $45 \%$ of the pie. They conclude that the anonymity hypothesis cannot explain the difference between their results and the findings of Forsyth et al. (1994) in DGs with full experimenter observation. Rather they suggest that the difference could be explained by apparently minor differences in respective designs regarding the possible choices available for subjects; in the "impunity game," there are a limited number of division choices; in the DG of Forsyth et al. (1994), the division is unrestricted. Bolton et al. [18] further explore this intuition by designing experiments that vary in the number of repetitions and the cardinal number of possible splitting. They conclude that dictators determine how much money they should keep, and consequently how much they should give in gifts, on the basis of the total amount available for the entire experimental session, and not on the basis of what is available per game. In other terms, dictators in the "impunity game" appear to be less generous than those in DG studies when considered on a per game basis. But when viewed on the basis of the entire experiment they appear equally, and therefore consistently, generous.

Other contributions by Bohnet and Frey [19, 20], Frohlich et al. [21], Burnham [22], and Haley and Fessler [23] test the recipient anonymity hypothesis in prisoner's dilemma, DGs, or UGs and show, again, that results are very sensible to experimental design. Although Frohlich et al. [21] support Hoffman et al. [14] findings that increasing anonymity across recipients reduces dictator's offers, they point out that DG experiments designed to create conditions of privacy and anonymity have a flaw, since they may engender doubts on subjects regarding the existence of pairings (such statements in the instructions as "you will not be paired with any of these people," meaning that subjects will be paired exclusively with people sitting in a different room may raise doubts about the very pairing. Note that this suggests that double-blind DG experiments lead to overestimating systematically the role of self-interest in individual's motivations, a claim which stands in complete contradiction with Lewitt and Levin [12]) and the disposition of any money they share. Bohnet and Frey [20] explore further the intuition of Hoffman et al. [24] that the language used to explain the experimental task affects "subjects" degree of social distance from the experimenter and expectations of reciprocity" [24, page 653]. They show that silent one-way identification suffices to raise solidarity in prisoner's dilemma and dictator games, suggesting that social distance (and not only expectations of reciprocity) matters. By contrast, Burnham [22] shows that reducing recipient anonymity may increase offers. Photographs, conceived as a "precise step from total anonymity towards the rich and uncontrolled communication of nonlaboratory experiments" [22, page 134], are introduced in a UG and induce results consistent with Schelling's "identifiable victim" that when people know more about the recipient, they give more. Moreover, they suggest that perceived privacy may be more important than the actual level of privacy (note that this is in line with recent findings in neurobiology [25] showing that behavior influenced by peers indicates a true change in attitude such that social influence induces a true change in perception and 
TABle 1: Payoffs of the sequence of DGs in Treatment 1.

\begin{tabular}{lccc}
\hline Players & \multicolumn{3}{c}{ Payoffs } \\
Step 1 & Step 2 & Step 3 \\
\hline $\mathrm{A}$ & $\mathrm{A} \rightarrow 10-p_{1}$ & $\mathrm{~A} \rightarrow 10-p_{2}$ & $\mathrm{~A} \rightarrow 10-p_{3}-S$ \\
$\mathrm{~B}$ & $\mathrm{~B} \rightarrow p_{1}$ & $\mathrm{~B} \rightarrow p_{2}$ & $\mathrm{~B} \rightarrow p_{3}$ \\
& $\mathrm{C} \rightarrow S$, \\
$\mathrm{C}$ & $\mathrm{C} \rightarrow 0$ & $\mathrm{C} \rightarrow E\left[G_{2}\right]$ with $1<G_{2}<5$ & if $S \leq \sum_{i=1}^{6}\left(10-p_{3}^{i}\right) / 6$ Or C $\rightarrow E\left[G_{3}\right]$ with, $1<G_{3}<5$ \\
& & $S>\sum_{i=1}^{6}\left(10-p_{3}^{i}\right) / 6$ \\
\hline
\end{tabular}

not merely a desire of conformity (see [26]). Haley and Fessler [23] introduce tacit visual cues in the form of stylized eyes or auditing cues (via the use of sound-deadening earmuffs) suggesting subjects that are being observed by others. They show that when using a computer displaying eyespots almost twice as many participants gave money to their partners in a DG as compared with the control treatment.

Other related papers explore the effect of different modes of communication between subjects. Ellingsen and Johannesson [27], Xiao and Houser [28, 29], Mohlin and Johannesson [30], and Andreoni and Rao [31] introduce the possibility of feedback (verbal written communication) from recipient to dictators. Results suggest that anticipated verbal feedback is equivalent to the effect of the recipient punishment power in UGs [27] or is an expression of disapproval that plays as a substitute for monetary punishments [28], but unfortunately does not permit to discriminate between interpretations of fairness in terms of social norms and "relationship" interpretations, which claim that communication increases empathy or decreases the social distance [30].

The remainder of the paper is organized as follows. In Section 2, we describe the two treatments that we ran. In Section 3, we compare the effects of the existence of a third party on the level of the propositions in the modified DGs and UGs. In Section 4, we focus on the level of sanctions as well as their effects on the propositions. In Section 5, we look at the receiver's behavior in the UG, and finally we discuss our results in Section 6.

\section{Description of the Two Treatments (Treatment 1 and Control Treatment)}

The two treatments that we ran are designed as follows.

The within design of Treatment 1 is made of two periods of three steps.

(i) The first period is a sequence of three DGs and consists of a first step where a proposer and a responder are alone, a second step where a proposer and a responder who both know that a third party (the observer) is informed about the sharing of the pie, and a third step identical to the second except that the observer is now allowed to sanction (at no cost) the proposer.

(ii) The second period is a sequence of three UGs with the same three steps as described for DGs.
In order to prevent responders from retaliating against proposers, we randomly matched responders at the beginning of the second period with one of the existing pair of proposer/observer. Although retaliation behavior is interesting in itself (in particular, it occurred during the pilot), we prefer to neutralize it in order to avoid pollution of the results.

Moreover, in order to avoid the reluctance to punish associated with costly sanctions, we assume that sanction is costless for the punisher. We are also justified in holding that social disapproval is not necessarily costly for those who sanction a given behavior. For instance, answering an opinion poll that asks a given question such as "would you say that the President's decision is: excellent, good, bad, very bad, no opinion" is not costly (if we except an opportunity cost that we may approximate to the show-up fee) and can be assimilated to a sort of sanction. Furthermore, the fact that citizens in democratic societies can sanction a politician by voting against him can be considered as costless for them. When a teacher gives low grades to bad pupils, it is not costly for him. Deciding to put a fine is not costly for the policeman even if it is so for the society (Bruno Frey suggests another experiment with both a constant cost of the sanctions and positive as well as negative sanctions. We also work on a between design as kindly suggested by Werner Güth and Jean-Louis Rullière.) We can give many examples that are in line with this idea of costless social sanctions.

Accordingly, the design of the Treatment 1 may be summarized as follows.

Each participant played the whole sequence of three DGs and three UGs five times one after the other.

All subjects were informed about the extensive form of the game and the exchange rate between Euros and ECU (experimental currency unit). The exchange rate was $1 \mathrm{ECU}$ $=0.1$ euro. Thus, Player A knew, for instance, that $\mathrm{C}$ will be informed about the sharing of the pie at the second step and that he could punish him at the third step of both the DG and UG. The experimental instructions can be found in Appendix A.1, and the payoffs are summarized in Table 1 (for the sequence of DGs) and Table 2 (for the sequence of UGs) below, where $p_{1}$ defines the offer of proposer (A) at the first step, $p_{2}$ at the second step, and $p_{3}$ at the third step of the DG. $p_{4}$ defines the offer of proposer (A) at the first step, $p_{5}$ at the second step, and $p_{6}$ at the third step of the UG. Finally, $\mathrm{S}$ defines the sanction (the amount $\mathrm{C}$ deducts from A's remaining share). 
TABLE 2: Payoffs of the sequence of UGs in Treatment 1.

\begin{tabular}{|c|c|c|c|}
\hline \multirow{2}{*}{ Players } & \multicolumn{3}{|c|}{ Payoffs } \\
\hline & Step 1 & Step 2 & Step 3 \\
\hline A & $\begin{aligned} \mathrm{A} \rightarrow & 10-p_{4} \\
& \text { or } \\
\mathrm{A} & \rightarrow 0\end{aligned}$ & $\begin{aligned} \mathrm{A} \rightarrow & 10-p_{5} \\
& \text { or } \\
\mathrm{A} & \rightarrow 0\end{aligned}$ & $\begin{aligned} \mathrm{A} \rightarrow & 10-p_{6}-S \\
& \text { or } \\
\mathrm{A} & \rightarrow 0 \\
& \text { or } \\
\mathrm{A} & \rightarrow-S\end{aligned}$ \\
\hline B & $\begin{array}{l}\mathrm{B} \rightarrow p_{4} \\
\quad \text { or } \\
\mathrm{B} \rightarrow 0\end{array}$ & $\begin{array}{l}\mathrm{B} \rightarrow p_{5} \\
\quad \text { or } \\
\mathrm{B} \rightarrow 0\end{array}$ & $\begin{array}{l}\mathrm{B} \underset{\mathrm{or}}{\rightarrow} p_{6} \\
\mathrm{~B} \stackrel{\rightarrow}{\rightarrow}\end{array}$ \\
\hline $\mathrm{C}$ & $\mathrm{C} \rightarrow 0$ & $\begin{array}{c}\mathrm{C} \rightarrow E\left[G_{5}\right] \\
\text { with } 1<G_{5}<5\end{array}$ & $\begin{array}{c}\mathrm{C} \rightarrow S, \\
\text { If } S \leq \max \left(10-p_{6}^{1}\right) \text { and } p_{6}=0 \text { or } \\
C \rightarrow E\left[G_{6}\right] \text { with } 1<G_{6}<5 \text { if } S>\max \left(10-p_{6}^{1}\right)\end{array}$ \\
\hline
\end{tabular}

Subjects received a show-up fee of 5 euro in all experiments; as it is the practice, this show-up fee is not considered part of type A players' endowment, but is included when we report subjects' average earnings in some of the results below. Moreover, in the second step of both the DG and the UG, the third party gets a random amount $G_{2}$ with $1<G_{2}<5$.

In order to avoid too obvious strategic behaviors, we implemented sanctioning rules. Because the sanctions are costless for the punishers, they have indeed the possibility to take all what the proposers keep. In the DG, the sanction cannot be greater than the mean of the remaining shares of all proposers, otherwise it is a random amount $G_{3}$ with 1 $<G_{3}<5$. In the UG, the sanction cannot be greater than the maximum of the remaining shares of proposers but can be equal to zero, otherwise it is a random amount $G_{6}$ with $1<G_{6}<5$ (see Figure 1(a)).

Subjects interacted anonymously and were never informed of other players' identities. The subjects were students or people who have voluntarily registered to the LEEP (Laboratoire d'Economie Expérimentale de Paris) platform dedicated to experimental economics at the University of Paris. Each subject participated in only one treatment.

The experiments were computerized using the REGATE software designed by Ferriol [32], and the program was set up by Maxim Frolov from the Centre d'Economie de la Sorbonne of the University of Paris 1.

The instructions (see Appendix A) were distributed and read aloud. The subjects then filled out a questionnaire that allowed their understanding of the rules of the game. They answered privately the questions. The answers were mainly correct and we read the right answers aloud.

The specific roles of proposer (A), recipient (B), and observer (C) were randomly assigned to the subjects inside 6 distinct groups drawn at random at the beginning of the experiment. Moreover, as already mentioned, subjects of type $\mathrm{B}$ were randomly reallocated in one of the existing group at the end of the first period.

Each session lasted roughly 1:30 $\mathrm{h}$ and subjects earned on average 95.71 ECU. We ran 6 sessions of Treatment 1 during the period December 2008 through January 2009 (the data of the experiments are available on the following site: http://hp.gredeg.cnrs.fr/Pierre_Garrouste/donneesCumulees Au23022009.xls. We have decided to eliminate seven (out of a total of 180) observations considered as too irrational. More precisely, they were corresponding to offers of 9 and 10 in the two first steps of the two games).

We also ran a Control Treatment (Treatment 2) that permits us to control for learning and partly for order effects. The design of this treatment is the following:

(i) a first step with three standard dictator games played successively followed by

(ii) a second step with three standard ultimatum games played successively.

Those two steps were run for five times, and 3 sessions were played on May 2010 (see Tables 3 and 4 and Appendix A.2).

\section{The Effects of the Existence of a Third Party on Offers in the Modified DGs and UGs}

Theoretically (see Tables 5 and 6 for the theoretical equilibrium payoffs), introducing a third party who is only informed about the sharing of the pie should have no effect on the proposer's offer in the DG as well as in the UG. The theoretical solution of the DG corresponds to a proposal of zero, that is,

$$
p_{j}^{i}=0, \quad \text { for } i=1, \ldots, 6, j=1,2
$$

(where $i$ defines the six As and $j$ the steps), while in the UG it corresponds to the minimum possible proposition (in our experiments, one ECU), that is.

$$
p_{j}^{i}=1, \quad \text { for } i=1, \ldots, 6, j=4,5,6 \text {. }
$$

The empirical results give a completely different picture; the existence of the third party increases the level of the propositions in the two games (see Appendices B, C, and $D$ for the statistics of the results). In the DG, the mean of the differences in terms of offers by the proposers between the case where the third party is not informed (the opaque 
TABle 3: Payoffs of the sequence of DGs in Control Treatment.

\begin{tabular}{lccc}
\hline Players & \multicolumn{3}{c}{ Payoffs } \\
& Step 1 & Step 2 & Step 3 \\
\hline $\mathrm{A}$ & $\mathrm{A} \rightarrow 10-p_{1}$ & $\mathrm{~A} \rightarrow 10-p_{2}$ & $\mathrm{~A} \rightarrow 10-p_{3}$ \\
$\mathrm{~B}$ & $\mathrm{~B} \rightarrow p_{1}$ & $\mathrm{~B} \rightarrow p_{2}$ & $\mathrm{~B} \rightarrow p_{3}$ \\
\hline
\end{tabular}

TABLE 4: Payoffs of the sequence of UGs in Control Treatment.

\begin{tabular}{lccc}
\hline Players & \multicolumn{3}{c}{ Payoffs } \\
& Step 1 & Step 2 & Step 3 \\
\hline \multirow{3}{*}{$\mathrm{A} \rightarrow 10-p_{4}$} & $\mathrm{~A} \rightarrow 10-p_{5}$ & $\mathrm{~A} \rightarrow 10-p_{6}$ \\
& or & or & or \\
B & $\mathrm{A} \rightarrow 0$ & $\mathrm{~A} \rightarrow 0$ & $\mathrm{~A} \rightarrow 0$ \\
& $\mathrm{~B} \rightarrow p_{4}$ & $\mathrm{~B} \rightarrow p_{5}$ & $\mathrm{~B} \rightarrow p_{6}$ \\
& $\mathrm{or}$ & or & or \\
& $\mathrm{B} \rightarrow 0$ & $\mathrm{~B} \rightarrow 0$ & $\mathrm{~B} \rightarrow 0$ \\
\hline
\end{tabular}

TABLE 5: Theoretical payoffs in each step $(1,2,3)$ of the sequence of DGs for players $\mathrm{A}, \mathrm{B}$, and $\mathrm{C}$.

\begin{tabular}{cccc}
\hline & A & B & C \\
\hline 1 & 10 & 0 & 0 \\
2 & 10 & 0 & $G_{2}$ \\
3 & 0 & 0 & 10 \\
\hline
\end{tabular}

TABLE 6: Theoretical payoffs in each step $(1,2,3)$ of the sequence of UGs for players A, B, and C.

\begin{tabular}{cccc}
\hline & A & B & C \\
\hline 1 & 9 & 1 & 0 \\
2 & 9 & 1 & $G_{5}$ \\
3 & 9 & 1 & $G_{6}$ \\
\hline
\end{tabular}

case) and the case where he is only informed (the open case) noted that $p_{2} p_{1}$ reaches 0.32 and is significantly different from zero $(\operatorname{Pr}(|T|>|t|)=0.03)$, and in the UG (noted $\left.p_{5} p_{4}\right)$, this mean is equal to 0.28 and is significantly different from zero $(\operatorname{Pr}(|T|>|t|=0.02)$ (see Appendix E). The mean of the differences between the case with sanctions and the open case is, respectively, 1.12 (with $\operatorname{Pr}(|T|>|t|)=0.00$ ) for the DG $\left(p_{3} p_{1}\right)$ and 0.34 for the UG $\left(p_{6} p_{4}\right)$ (with $\operatorname{Pr}(|T|>|t|)=0.02$ ) (see Appendix E).

In the Control Treatment (where the theoretical equilibria are, respectively, a nil offer in the DG and an offer of $1 \mathrm{ECU}$ in the UG), the respective values are the following: for the standard DG the mean of the differences between the second and the first steps is -0.20 but is not significant $(\operatorname{Pr}(|T|>$ $|t|)=0.16$ ), and the mean of the differences between the third and the second steps is 0.01 and is also not significant $(\operatorname{Pr}(|T|>|t|)=0.91)$ (see Appendix E). This is very different from the results obtained in Treatment 1, and this suggests that the presence of an observer impacts on the proposer's behavior. For the standard UG the means are significant (resp. $0.28(\operatorname{Pr}(|T|>|t|)=0.02)$ and $0.23(\operatorname{Pr}(|T|>|t|)=0.01)$, but when the propositions are accepted this mean becomes -0.04 and is not significant $(\operatorname{Pr}(|T|>|t|)=0.46)$. When a proposition is refused, the next proposition is higher and the mean of the differences between the two propositions (the next proposition minus the refused one) is 1.04 and is highly significant $(\operatorname{Pr}(|T|>|t|)=0.00)$. This is in line with the standard results. We will discuss the results below.

What we also found interesting is that for Treatment 1, the regressions of the differences between offers in the case of sanctions and the open case on the differences between the proposals in the open case and the opaque case suggest that the existence of a third party increases (at the margin) offers by proposers more than the sanction does. When we regress the differences (in both the DG and the UG) between the sanction case and the open one on the opaque case and the open one, we obtain a coefficient of -0.41 in the DG and of -0.37 in the UG (see Appendix G). This means that the marginal effect of the presence of a third party being informed about the sharing of the pie is higher than the marginal effect of being sanctioned by the same third party. In other words, as far as the level of offers is concerned, the higher is the marginal effect of being observed by someone, the lower is the marginal effect of the sanction. This result suggests the existence of self-reputational motives guiding individual behavior (see, e.g., [33]).

\section{Third Party's Sanctions in Modified DGs and UGs}

As we already discussed, there is only one possible equilibrium resulting from the sequence of DGs played in Treatment 1 (see Table 5). It corresponds to the situation where the proposer keeps the whole pie. In this case, the sanction $S$ is equal to the size of the pie and the proposer gets nothing. This equilibrium corresponds to a gain of 0 for every proposer and the responder and 10 for the third party. The reasoning is as follows. if one of the proposers keeps less than 10, say 9, the mean of the amounts the proposers want to keep is 9.83 . In this case, the proposer who keeps 9 may encounter a loss of -.83 (because the third party can take up to 9.83) while the others can win (10-9.83). Therefore, he had better not to deviate from keeping the whole pie. The other solution could be when the proposers keep a value less or equal to $E\left[G_{3}\right]\left(G_{3}\right.$ is what the third party obtains when his sanction is strictly higher than the average value which the six proposers want to keep in the DG. In the UG, $G_{3}$ is what the third party obtains when the responder accepts the offer or when his sanction is strictly higher than the highest value of what the proposers want to keep if the responder refuses the proposer's offer. In the two games, it is defined as a random value drawn between 1 and 5). In this case, the third party has no interest to punish the proposer, since he obtains less (the sanction) than what the random draw gives him. This solution is however unstable because the proposers are better off if they keep a higher amount. Just because the sanction needs to be less than the mean of the amount kept by all proposers, if five proposers decide to keep, say 3 , the sixth proposer has interest to keep 4 since the mean is 3.16 and since, according to the rules of the game, the third party cannot take him higher than 3.16. But the other proposers have also interest to keep 4. This reasoning can be reproduced until 10 is reached. 
Two-sample Wilcoxon rank-sum (Mann-Whitney) test

\begin{tabular}{c|ccc} 
var2 & Obs & Rank sum & Expected \\
\hline 1 & 124 & 16524 & 15438 \\
2 & 124 & 14352 & 15438 \\
\hline Combined & 248 & 30876 & 30876 \\
Unadjusted variance & 319052.00 & \\
Adjustment for ties & $\frac{-21031.43}{298020.57}$ & \\
Adjusted variance & &
\end{tabular}

$$
\begin{aligned}
& \text { Ho: } \operatorname{prop} 1(\operatorname{var} 2==1)=\operatorname{prop} 1(\operatorname{var} 2==2) \\
& z=1.989
\end{aligned}
$$

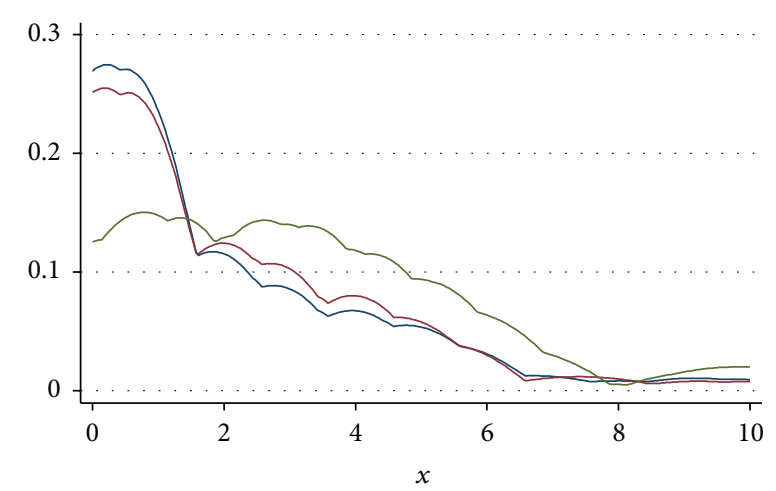

— $\begin{aligned} & \text { kdensity } p_{1} \\ & \text { kdensity } p_{3}\end{aligned} \quad-$ kdensity $p_{2}$

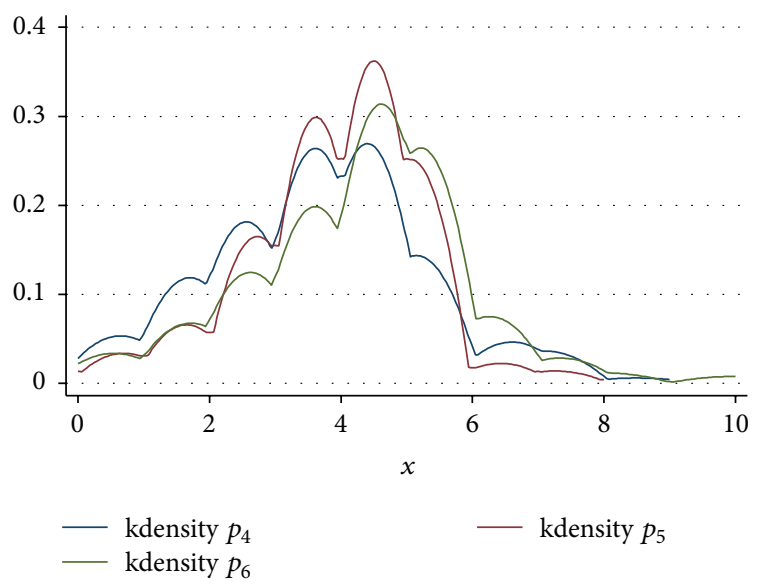

FIGURE 1

More generally a proposer $i$ if rational has to keep

$$
10-p_{3}^{i}<\frac{\sum_{i=1}^{6}\left(10-p_{3}^{i}\right)}{6}
$$

That is

$$
\frac{\sum_{i=1}^{6} p_{3}^{i}}{6}>p_{3}^{i} .
$$

This condition holds, and we obtain a unique equilibrium if and only if

$$
p_{3}^{i}=0 \quad \forall i=1, \ldots, 6
$$

The unique equilibrium has the following characteristics. the proposers keep 10 and the third parties' sanctions (SDG, for sanction in the DG) are 10. For the UG, the result is slightly different. The proposer offers 9 , which the responder accepts (the perfect subgame equilibrium), and the third party cannot sanction (SUG, for sanction in the UG) the proposer just because the recipient accepts the offer. 
TABle 7

\begin{tabular}{ccccr}
\hline & Step 1 & Step 2 & Step 3 & Total for period 1 \\
\hline A & $10-p_{1}$ & $10-p_{2}$ & $10-p_{3}-S$ & $30-p_{1}-p_{2}-p_{3}-S$ \\
B & $p_{1}$ & $p_{2}$ & $p_{3}$ & $p_{1}+p_{2}+p_{3}$ \\
C & 0 & $G_{2}$ & $S$ if $S \leq \operatorname{avg}\left(10-p_{3}\right)$ otherwise $G_{3}$ & $G_{2}+S$ or $G_{2}+G_{3}$ \\
\hline
\end{tabular}

TABle 8

\begin{tabular}{|c|c|c|c|c|}
\hline & Step 1 & Step 2 & Step 3 & Total for the period 2 \\
\hline A & $10-p_{1}$ or 0 & $10-p_{1}$ or 0 & $10-p_{3}-S$ or 0 & $\begin{array}{c}30-p_{1}-p_{2}-p_{3}-S \text { or } 0 \text { or } \\
20-p_{1}-p_{2} \text { or } 20-p_{2}-p_{3} \\
\text { or } \\
20-p_{1}-p_{3} \text { or } \\
20-p_{1}-p_{2}-S \text { or } \\
20-p_{2}-p_{3}-S \text { or } \\
10-p_{1}-S \text { or } \\
10-p_{2}-S \text { or } 10-p_{3}-S \text { or } \\
0-S\end{array}$ \\
\hline B & $p_{1}$ or 0 & $p_{2}$ or 0 & $p_{3}$ or 0 & $\begin{array}{c}p_{1}+p_{2}+p_{3} \text { or } 0 \text { or } p_{1} \text { or } p_{2} \\
\text { or } p_{3} \text { or } p_{1}+p_{2} \text { or } p_{2}+p_{3} \\
\text { or } p_{1}+p_{3}\end{array}$ \\
\hline $\mathrm{C}$ & 0 & $G_{5}$ & $\begin{array}{c}S \text { if } p_{3}=0 \text { and } \\
S \leq \max \left(10-p_{3}\right) \\
\text { otherwise } G_{6}\end{array}$ & $\begin{array}{c}G_{5}+G_{6} \\
\text { or } \\
G_{5}+S\end{array}$ \\
\hline
\end{tabular}

The empirical results tell a different story. If the mean of the sanctions (S) is 4.37 for the DG and 4.78 for the UG (the difference between the two equals 0.41 and is significant $(\operatorname{Pr}(|T|>|t|)=0.094)$, the mean of the corresponding offers are, respectively, 2.49 and 4.25 for the DG and the UG. The first result (the means of the sanctions) is due to the difference between the rules governing sanctions in the two games, respectively. In the DG, the sanction needs not to be higher than the mean of the amounts kept by the proposers, whereas in the UG it needs not to be higher than the highest amount kept by the proposers. It seems rational for the third parties to punish more in the modified UG than in the modified DG. What is however interesting is that whereas sanctions rules are different, the effect of the existence of a third party is not affected by this difference. The difference between the offers in the two games is due to the fact that in the UG, responders are allowed to refuse offers from proposers even in the two first steps of the game when no sanction is allowed. The differences between offers made at the same steps in the two games give a strange result. If the differences are the same in the two first steps (2.33 and 2.31, resp.), the difference between the third steps is less important (1.4). Accordingly, the effect of the difference in the rules of sanctioning is less important than the effect of the difference in the rules of the game (to be allowed or not to refuse the offers).

Another result lies in the relations between sanctions and offers. When we regress (we have tested positively the normality of the distribution. We then have used an OLS regression) the last propositions on the second ones and on the sanctions, we find a negative and significant relationship between the last proposition and the sanction in the ultimatum game $(-0.18)$ (no significant relationship between the last proposition and the previous one), but a positive and significant one between the last proposition and the second one in the dictator game (0.038) and no significant relationship between the last proposition and the sanction (see Appendix F). We find similar result when we test the two following models:

(i) $p_{3}=\alpha_{d} \cdot p_{1}+\beta_{d} \cdot p_{2}+\mu_{d} \cdot \mathrm{SDG}+b_{d}$

(ii) $p_{6}=\alpha_{u} \cdot p_{4}+\beta_{u} \cdot p_{5}+\mu_{u} \cdot \mathrm{SUG}+b_{u}$,

where $\beta_{d}$ and $\mu_{u}$ are both significant $(0.31$ and -0.18 , resp.) but the other parameters are not.

That means that the first offers do not influence the third ones in both games and that although the second assignments to $B$ do not influence the third ones in the UG, they do in the DG. Finally the level of the sanction influences the last assignments but only in the UG.

\section{The Second Party's "Sanctions" in the UG in the Two Treatments}

Theoretically, the recipient rejects the proposition only if it is nil. If rational, he/she has to accept all nonnil propositions. In Treatment 1, the percentage of rejected propositions is $27.4 \%$. The average level of propositions that are rejected is 2.49 with standard deviation of 0.13 , while the mean of the level of the propositions that are accepted is 4.29 with standard deviation of 1.29. We see that the accepted propositions are not far from a fifty-fifty solution. This is a classical experimental result. We controlled for the gender and the age and found no significant impacts.

The number of the propositions that are rejected is significantly different in the Control Treatment as compared to Treatment 1 (22.2\% and $27.4 \%$, resp.). The average level 
of the propositions that are rejected is 2.41 (with standard deviation of 1.45), whereas the average level of propositions that are accepted is 3.92 (standard deviation of 1.29).

\section{Discussion}

Our experimental design allows us to validate some now well-accepted experimental findings on one hand, and to obtain interesting new results on the other hand. The results, however, depend on the type of game involved. Some of them are valid in the DG as well as in the UG, but others are only observed in the DG. What is common to the two games lies in the fact that they diverge significantly from theoretical results. The offers are never nil in the DG and never equal to one ECU in the UG.

We also show that sanctions are efficient; proposers are induced to increase their offers in the fear of monetary losses. In the UG, offers are always higher than predicted by the perfect subgame equilibrium. Those two findings are well documented in the literature. What is however more surprising and original is the idea that in the DG, individuals increase their offers when they know that somebody else knows the level of their offer. Consequently, the percentage of individuals whose propositions increase from one step to the next is always higher than the percentage of those whose propositions decrease (see Appendix D). Moreover, the difference between the propositions in the second and first steps in the two games played Treatment 1 (i.e., $p_{2} p_{1}$ in the DG and $p_{5} p_{4}$ in the UG) is significantly positive. This "somebody is watching you" effect must be supplemented by the fact that the more the effect of "being regarded by others" the less the effect of the sanction and vice versa. The fact that subjects' choices are modified when they are scrutinized can corroborate the two theoretical interpretations we have already in our introductory survey of related literature. First, individuals' behavior may be considered as guided by selfreputational motives $[15,16,33]$. Second, individuals can be conceived as strong reciprocators [34] in the sense that they internalize the possible reactions of others; the fact that somebody is aware of my decisions makes me behaving in conformity with what the others consider as fair. It is the reason why the more they react to people scrutiny the less they react to expected sanction, just because they internalize a norm of fairness.

What seems however confusing lies in the fact that in the UG, we do not find similar findings. Appendix D shows that while the percentages of proposers who increase their offers are higher in the two games (DG and UG) in Treatment 1 than those who decrease them, it is the opposite in the Control Treatment, but only for the DG. Moreover, if the difference between the first and the second offers, as well as between the third and the second in the DG, is significantly positive in Treatment 1 but not the Control Treatment, those differences are always significant in the UG and in the two kinds of experiments ( 1 and 2 ). This result shows that the UG is more complex, because the proposer first takes into account the risk that the receiver may reject his/her offer and second increases his/her offer in case of rejection. Everything is as if those two effects were at least as important as the "somebody is watching you" effect.

Finally, we need to explain why the sanctions are negatively related with the offers in the UG and not in the DG. In the UG, the relation is intuitive since the higher the offer the less the sanction. This result is in line with the interpretation that individuals (here, the third parties) are reciprocators and accordingly, when proposers expect a sanction they increase their offers. This effect is however impossible to identify precisely, because it is blended with the expectation of the proposer regarding the receiver's decision (he accepts or refuses). What is less intuitive is that in the DG, the proposers do not seem to be reactive to sanction. The explanation lies in the fact that the dictator seems more sensible to observation than to sanction. Another explanation might be that third parties internalize dictators' behaviors as being truly "unfair," and that dictators know that they are perceived this way. This explanation is corroborated by the fact that in $21.1 \%$ of the cases the sanctions are nil as compared to $3.8 \%$ in the UG.

Those results need however to be strengthened by further investigation. A first improvement could be made by designing DG experiments that permit to discriminate more accurately between interpretations in terms of conformity and in terms of social distance ("somebody is watching you" effect) and to better control for order effects. Then we plan to run UG experiments that permit to disentangle the relative effects of subjects' attitude towards risk and observation by a third party.

\section{Appendices}

\section{A. Instructions}

A.1. Instructions for Treatment 1. This is an experience on decision making within a group. If you follow the instructions carefully, you could win money which would be paid in cash at the end of the experience.

ECU (experimental currency unit) is the currency used during the experience, and all conversions will be made in ECU. At the end of the session, your profit will be paid in euros at the rate of $1 \mathrm{ECU}=0.1$ euro.

You will participate in the experience for 5 times of two periods each. Prior to the first period, the participants are divided randomly into groups of 3. Therefore, there are 6 groups of three participants each. Within each group, each participant will be identified by a letter A, B, or C. The decisions to be made by each participant during the two periods are detailed in the remaining instructions. At the end of the first period, the Bs are redistributed randomly within the groups, while the As and Cs are not. At the end of the second period, the roles will be reassigned randomly and both periods are played 5 times.

The first period contains three steps carried out as follows.

Step 1. C does not participate in this step. A receives 10 ECUs. A has the possibility of sending part of this amount to B, namely $x_{1}$, the amount sent to $\mathrm{B}$ from $\mathrm{A}$. At the end of this first step, A has $10-p_{1}$ ECU and B has $p_{1}$ ECU. 
- $t$ test $p_{2} p_{1}==0$

One-sample $t$ test

\begin{tabular}{|c|c|c|c|c|c|c|}
\hline Variable & Obs & Mean & Std. err. & Std. dev. & \multicolumn{2}{|c|}{ [95\% conf. interval] } \\
\hline$p_{2} p_{1}$ & 135 & -0.2074074 & 0.1468656 & 1.706425 & -0.4978821 & 0.0830673 \\
\hline \multicolumn{2}{|c|}{$\begin{aligned} \text { Mean } & =\text { mean }\left(p_{2} p_{1}\right) \\
\text { Ho: } \text { mean } & =0\end{aligned}$} & & & & \multicolumn{2}{|c|}{$\begin{array}{r}t=-1.4122 \\
\text { Degrees of freedom }=134\end{array}$} \\
\hline \multicolumn{2}{|c|}{$\begin{array}{c}\text { Ha: mean }<0 \\
\operatorname{Pr}(T<t)=0.0801\end{array}$} & \multicolumn{3}{|c|}{$\begin{array}{c}\text { Ha: mean } !=0 \\
\operatorname{Pr}(|T|>|t|)=0.1602\end{array}$} & \multicolumn{2}{|c|}{$\begin{array}{c}\text { Ha: mean }>0 \\
\operatorname{Pr}(T>t)=0.9199\end{array}$} \\
\hline
\end{tabular}

- $t$ test $p_{3} p_{2}==0$

One-sample $t$ test

\begin{tabular}{c|rccccc}
\hline Variable & Obs & Mean & Std. err. & Std. dev. & \multicolumn{2}{c}{ [95\% conf. interval] } \\
\hline$p_{3} p_{2}$ & 135 & 0.0148148 & 0.1346474 & 1.564462 & -0.2514943 & 0.2811239 \\
\hline $\begin{array}{c}\text { Mean }=\text { mean }\left(p_{3} p_{2}\right) \\
\text { Ho: mean }=0\end{array}$ & & & & Degrees of freedom $=134$ \\
\end{tabular}

Ho: mean $=0$

Ha: mean $<0$ $\operatorname{Pr}(T<t)=0.5437$
Ha: mean ! =0 $\operatorname{Pr}(|T|>|t|)=0.9126$
Degrees of freedom $=134$

Ha: mean $>0$ $\operatorname{Pr}(T>t)=0.4563$

- $t$ test $p_{5} p_{4}==0$

One-sample $t$ test

\begin{tabular}{|c|c|c|c|c|c|c|}
\hline Variable & Obs & Mean & Std. err. & Std. dev. & \multicolumn{2}{|c|}{ [95\% conf. interval] } \\
\hline$p_{5} p_{4}$ & 135 & 0.2814815 & 0.122464 & 1.422904 & 0.039269 & 0.523694 \\
\hline
\end{tabular}

Ho: mean $=0$

Ha: mean $<0$

$\operatorname{Pr}(T<t)=0.9885$
Ha: mean $!=0$ $\operatorname{Pr}(|T|>|t|)=0.0231$
Ha: mean $>0$

$\operatorname{Pr}(T>t)=0.0115$

- $t$ test $p_{6} p_{5}==0$

One-sample $t$ test

\begin{tabular}{|c|c|c|c|c|c|c|}
\hline Variable & Obs & Mean & Std. err. & Std. dev. & \multicolumn{2}{|c|}{ [95\% conf. interval] } \\
\hline$p_{6} p_{5}$ & 135 & 0.237037 & 0.0970587 & 1.12772 & 0.0450719 & 0.4290022 \\
\hline \multicolumn{2}{|c|}{$\begin{aligned} \text { Mean } & =\text { mean }\left(p_{6} p_{5}\right) \\
\text { Ho: } \text { mean } & =0\end{aligned}$} & & & & \multicolumn{2}{|c|}{$\begin{array}{r}t=2.4422 \\
\text { Degrees of freedom }=134\end{array}$} \\
\hline \multicolumn{2}{|c|}{$\begin{array}{c}\text { Ha: mean }<0 \\
\operatorname{Pr}(T<t)=0.9920\end{array}$} & \multicolumn{3}{|c|}{$\begin{array}{c}\text { Ha: mean } !=0 \\
\operatorname{Pr}(|T|>|t|)=0.0159\end{array}$} & \multicolumn{2}{|c|}{$\begin{array}{c}\text { Ha: mean }>0 \\
\operatorname{Pr}(T>t)=0.0080\end{array}$} \\
\hline
\end{tabular}

Figure 2

Step 2. A receives 10 ECUs once again. A can choose to send part of this amount to $\mathrm{B}$, namely $x_{2}$, the amount sent to $\mathrm{B}$ from A. C is informed of the value of the amount $p_{2}$ that $\mathrm{A}$ chose to send to $B$. $C$ receives a random amount between 1 and 5 ECUs. At the end of this step, A has $\left(10-p_{2}\right)$ ECU and $\mathrm{B}$ has $p_{2} \mathrm{ECU}$ and $\mathrm{C}$ has the random amount between 1 and 5 ECUs, the amount of which is represented by $G_{2}$.

Step 3. A receives 10 ECUs. A can choose to send part of this amount to B, namely $x_{3}$, the amount sent to B from A. C is informed of the value of the amount $p_{3}$ that $A$ chose to send to $\mathrm{B}$. C has the possibility of withdrawing from As profit, a share of the amount $\left(10-p_{3}\right)$ that A keeps, the amount of which is represented by $S$. During the third step, the profits are as follows. A keeps a profit equal to $10-p_{3}-S$. B has a profit equal to $p_{3}$. C makes a profit equal to $S$ if $S$ is less than or equal to the average of the $6\left(10-p_{3}\right)$ proposed by the six As who are participating in the experience, otherwise it is a random amount $G_{3}$ of between 1 and 5 .

At the end of the third step, the profits are calculated for all participants of the first period and then the second period is started. See Table 7.

\section{Example 1}

Step 1. A receives 10. A gives 0 to $\mathrm{B}$. A obtains $10-0$ and $\mathrm{B} 0$ $\left(p_{1}=0\right)$. 
TABLE 9

\begin{tabular}{lccccc}
\hline Variable & Obs & Mean & Std. Dev. & Min & Max \\
\hline$p_{1}$ & 173 & 1.34104 & 1.750214 & 0 & 6 \\
$p_{2}$ & 173 & 1.66474 & 2.149303 & 0 & 10 \\
$p_{3}$ & 173 & 2.791908 & 2.527188 & 0 & 10 \\
$p_{4}$ & 173 & 3.647399 & 1.594852 & 0 & 8 \\
$p_{5}$ & 173 & 3.936416 & 1.299151 & 0 & 8 \\
\hline$p_{6}$ & 173 & 4.283237 & 1.672488 & 0 & 10 \\
\hline$p_{2} p_{1}$ & 173 & .3236994 & 1.961657 & -5 & 10 \\
$p_{3} p_{2}$ & 173 & 1.127168 & 2.733515 & -10 & 10 \\
$p_{3} p_{1}$ & 173 & 1.450867 & 2.845674 & -5 & 10 \\
$p_{5} p_{4}$ & 173 & .2890173 & 1.652252 & -5 & 5 \\
$p_{6} p_{5}$ & 173 & .3468208 & 2.030567 & -6 & 9 \\
\hline$p_{6} p_{4}$ & 173 & .6358382 & 2.196797 & -6 & 10 \\
\hline
\end{tabular}

TABLE 10

\begin{tabular}{lccccc}
\hline Variable & Obs & Mean & Std. Dev. & Min & Max \\
\hline$p_{1}$ & 135 & 1.459259 & 1.972811 & 0 & 10 \\
$p_{2}$ & 135 & 1.251852 & 1.567956 & 0 & 6 \\
$p_{3}$ & 135 & 1.266667 & 1.920821 & 0 & 10 \\
$p_{4}$ & 135 & 3.22963 & 1.786937 & 0 & 7 \\
$p_{5}$ & 135 & 3.51111 & 1.434473 & 0 & 7 \\
\hline$p_{6}$ & 135 & 3.748148 & 1.391437 & 0 & 8 \\
\hline$p_{2} p_{1}$ & 135 & -.2074074 & 1.706425 & -10 & 5 \\
$p_{3} p_{2}$ & 135 & .0148148 & 1.564462 & -5 & 9 \\
$p_{3} p_{1}$ & 135 & -.1925926 & 1.528321 & -10 & 5 \\
$p_{5} p_{4}$ & 135 & .2814815 & 1.422904 & -4 & 4 \\
$p_{6} p_{5}$ & 135 & .237037 & 1.12772 & -3 & 5 \\
\hline$p_{6} p_{4}$ & 135 & .5185185 & 1.647485 & -5 & 5 \\
\hline
\end{tabular}

TABLE 11

\begin{tabular}{ccccccc}
\hline & $p_{2} p_{1}$ & $p_{3} p_{2}$ & $p_{3} p_{1}$ & $p_{5} p_{4}$ & $p_{6} p_{5}$ & $p_{6} p_{4}$ \\
\hline$p_{2} p_{1}$ & 1.0000 & & & & & \\
$p_{3} p_{2}$ & -0.3005 & 1.0000 & & & & \\
$p_{3} p_{1}$ & 0.4007 & 0.7535 & 1.0000 & & & \\
$p_{5} p_{4}$ & -0.0111 & 0.0060 & -0.0019 & 1.0000 & & \\
$p_{6} p_{5}$ & -0.0517 & 0.0737 & 0.0352 & -0.3021 & 1.0000 & \\
$p_{6} p_{4}$ & -0.0561 & 0.0726 & 0.0311 & 0.4729 & 0.6971 & 1.0000 \\
\hline
\end{tabular}

TABLE 12

\begin{tabular}{ccccccc}
\hline & $p_{2} p_{1}$ & $p_{3} p_{2}$ & $p_{3} p_{1}$ & $p_{5} p_{4}$ & $p_{6} p_{5}$ & $p_{6} p_{4}$ \\
\hline$p_{2} p_{1}$ & 1.0000 & & & & & \\
$p_{3} p_{2}$ & -0.5663 & 1.0000 & & & & \\
$p_{3} p_{1}$ & 0.5368 & 0.3913 & 1.0000 & & & \\
$p_{5} p_{4}$ & -0.0127 & -0.0220 & -0.0367 & 1.0000 & & \\
$p_{6} p_{5}$ & -0.0635 & 0.2729 & 0.2085 & -0.1814 & 1.0000 & \\
$p_{6} p_{4}$ & -0.0544 & 0.1678 & 0.1111 & 0.7395 & 0.5278 & 1.0000 \\
\hline
\end{tabular}

Step 2. A receives 10. A gives 3 to $\mathrm{B}$. A obtains $7, \mathrm{~B} 3$ and $\mathrm{C}$ a profit between 1 and 5 .
TABLE 13

\begin{tabular}{|c|c|c|c|c|c|c|}
\hline & $p_{2} p_{1}$ & $p_{3} p_{2}$ & $p_{3} p_{1}$ & $p_{5} p_{4}$ & $p_{6} p_{5}$ & $p_{6} p_{4}$ \\
\hline Equal 0 & 55.6 & 36.5 & 39.3 & 40.4 & 43.8 & 27.0 \\
\hline Negative & 19.7 & 17.4 & 13.3 & 22.5 & 23.0 & 25.3 \\
\hline Positive & 24.7 & 46.1 & 47.2 & 37.1 & 33.1 & 47.8 \\
\hline \multicolumn{7}{|c|}{ TABLE 14} \\
\hline & $p_{2} p_{1}$ & $p_{3} p_{2}$ & $p_{3} p_{1}$ & $p_{5} p_{4}$ & $p_{6} p_{5}$ & $p_{6} p_{4}$ \\
\hline Equal 0 & 61.5 & 65.2 & 57.8 & 43.7 & 47.4 & 36.3 \\
\hline Negative & 24.4 & 18.5 & 25.2 & 20.0 & 20.7 & 20.7 \\
\hline Positive & 14.1 & 16.3 & 17.0 & 36.3 & 31.9 & 43.0 \\
\hline
\end{tabular}

TABLE 15

\begin{tabular}{lcc}
\hline Treatment & $\begin{array}{c}\text { Mean of the Differences } \\
\text { between the propositions }\end{array}$ & values \\
\hline \multirow{3}{*}{1} & $2-1$ & $\mathbf{. 3 2 3}$ \\
& $3-2$ & $\mathbf{( 0 . 0 3 1 )}$ \\
& & $\mathbf{1 . 1 2 7}$ \\
& & $\mathbf{( 0 . 0 0 0 )}$ \\
Control & & -.207 \\
& & $(0.16)$ \\
& $3-2$ & .0148 \\
& & $(0.912)$ \\
\hline
\end{tabular}

Inside parenthesis the values of $\operatorname{Pr}(|T|>|t|)$.

In bold values significant (at $1 \%$ or $5 \%$ ).

TABLE 16

\begin{tabular}{lccc}
\hline \multirow{2}{*}{ Treatment } & $\begin{array}{l}\text { Mean of the Differences } \\
\text { between the propositions }\end{array}$ & \multicolumn{2}{c}{ Decisions } \\
\hline \multirow{3}{*}{$5-4$} & -.435 & $\mathbf{1 . 3 6 7}$ \\
& & $\mathbf{( 0 . 0 0 1 )}$ & $\mathbf{( 0 . 0 0 0 )}$ \\
& $6-5$ & -.142 & $\mathbf{1 . 4 2 5}$ \\
& & $(0.084)$ & $\mathbf{( 0 . 0 0 2 )}$ \\
Control & $5-4$ & -.345 & $\mathbf{1 . 6 5 3}$ \\
& & $\mathbf{( 0 . 0 0 7 )}$ & $\mathbf{( 0 . 0 0 0 )}$ \\
& $6-5$ & .0142 & $\mathbf{1 . 1 7 9}$ \\
& & $(0.918)$ & $\mathbf{( 0 . 0 0 0 )}$ \\
\hline
\end{tabular}

Inside parenthesis the values of $\operatorname{Pr}(|T|>|t|)$.

In bold values significant (at $1 \%$ or $5 \%$ ).

Step 3. A receives 10. A gives 3 to $B$. If the average donations to B is $5, \mathrm{C}$ can take $S$ such as $3 \leq S \leq 7$ to A. In this case, A obtains $7-S$, B obtains 3 and $\mathrm{C}$ obtains $S$, if $S \leq 5$ (average of donations to $\mathrm{B}$ ), otherwise $\mathrm{A}$ receives an amount between 1 and 5.

The second period has two steps carried out as follows.

Step 1. C does not participate in this step. A receives 10 ECUs. $\mathrm{C}$ has the possibility of sending part of this amount to $\mathrm{B}$, namely $p_{1}$, the amount sent to $B$ from $A$. B can accept or 
TABLE 17

\begin{tabular}{lcc}
\hline & $p_{3}$ & $p_{6}$ \\
\hline$p_{2}$ & $0.372^{* * *}$ & \\
& $(0.08)$ & \\
SDG & 0.081 & \\
& $(0.06)$ & 0.164 \\
$p_{5}$ & & $(0.09)$ \\
& & $-0.179^{* *}$ \\
SUG & & $(-0.07)$ \\
& & $4.463^{* * *}$ \\
_cons & $1.906^{* * *}$ & $(0.50)$ \\
& $(0.35)$ & \\
\hline
\end{tabular}

TABle 18

\begin{tabular}{lccc}
\hline & $p_{3} p_{2}$ & $p_{3} p_{1}$ & $p_{3} p_{1}$ \\
\hline$p_{2} p_{1}$ & $-0.419^{* * *}$ & & $0.581^{* * *}$ \\
& $(0.102)$ & & $(0.102)$ \\
$p_{3} p_{2}$ & & $0.784^{* * *}$ & \\
& & $(0.052)$ & \\
_cons & $1.263^{* * *}$ & $0.567^{* * *}$ & $1.263^{* * *}$ \\
& $(0.202)$ & $(0.154)$ & $(0.202)$ \\
$r 2$ & 0.090 & 0.568 & 0.161 \\
\hline
\end{tabular}

TABle 19

\begin{tabular}{lccc}
\hline & $p_{6} p_{5}$ & $p_{6} p_{4}$ & $p_{6} p_{4}$ \\
\hline$p_{5} p_{4}$ & $-0.371^{* * *}$ & & $0.629^{* * *}$ \\
& $(0.090)$ & & $(0.090)$ \\
$p_{6} p_{5}$ & & $0.754^{* * *}$ & \\
& & $(0.059)$ & \\
_cons & $0.454^{* * *}$ & $0.374^{* *}$ & $0.454^{* * *}$ \\
& $(0.150)$ & $(0.122)$ & $(0.150)$ \\
$r 2$ & 0.091 & 0.486 & 0.224 \\
\hline
\end{tabular}

refuse this share. If $\mathrm{B}$ refuses, $\mathrm{A}$ and $\mathrm{B}$ gain nothing. If $\mathrm{B}$ accepts, A has $10-p_{1}$ ECU and B has $p_{1}$ ECU.

Step 2. A receives 10 ECUs again. A can choose to send part of this amount to $B$, namely $p_{2}$, the amount sent to $B$ from $A$. $B$ can accept or refuse this share. If $B$ refuses, $A$ and $B$ gain nothing. If $\mathrm{B}$ accepts, $\mathrm{A}$ has $10-p_{2} \mathrm{ECU}$ and $\mathrm{B}$ has $p_{2} \mathrm{ECU}$. $\mathrm{C}$ is informed of the value of the amount $p_{2}$ that $\mathrm{A}$ chose to send to $B$. C receives an amount equal to $5 \mathrm{ECU}$ if $\mathrm{B}$ refuses the share or a random amount between 1 and 5 ECUs if B accepts the share.

Step 3. A receives 10 ECUs again. A can choose to send part of this amount to $\mathrm{B}$, namely $p_{3}$, the amount sent to $\mathrm{B}$ from A. B can accept or refuse this share. If $B$ refuses, $A$ and $B$ gain nothing. If $\mathrm{B}$ accepts, $\mathrm{A}$ has $10-p_{3}$ and $\mathrm{B}$ has $p_{3}$. C is informed of the value of the amount $p_{3}$ that $\mathrm{A}$ chose to send to B. C has the possibility of receiving an amount on A's profit, represented by $S$. During the third step, the profits are as follows. A keeps a profit equal to $10-p_{3}-S$ if B accepts the share or $0-S$ if $\mathrm{B}$ refuses it. $\mathrm{B}$ has a gain equal to $p_{3}$ if he accepts the share and 0 otherwise. $\mathrm{C}$ makes a profit equal to
$S$ if the share is not made, that is to say if B refuses it and if $S$ is less than the highest value $\left(10-p_{3}\right)$ that the A participants who are making the experiment keep, otherwise $\mathrm{C}$ receive a random amount $G_{6}$ which is between 1 and 5 .

At the end of the third step, the profits are calculated for all the participants of the second period. See Table 8.

\section{Example 2}

Step 1. A receives 10. A gives 4 to B. If $\mathrm{B}$ accepts, B obtains 4 and $A$ obtains 6 . If $B$ refuses, $A$ and $B$ have 0 .

Step 2. A receives 10. A give 5 to $B$. If $B$ accepts, $B$ obtains 5 and $A$ obtains 5. If B refuses, $A$ and $B$ have 0 . In both cases, $C$ obtains a profit between 1 and 5 .

Step 3. A receives 10. A gives 3 to $B$. If $B$ accepts, $B$ obtains 3 , A obtains 7 , and $C$ obtains a profit between 1 and 5 . If $B$ refuses, A obtains $0-S$ and $C$ obtains $S$. If, for example, the maximum number of proposals made to $\mathrm{B}$ is 5 and $S=4$ then A loses 4 , $\mathrm{B}$ obtains nothing, and $\mathrm{C}$ obtains 4 .

A.2. Instructions for the Control Treatment. This is an experience on decision making within a group. If you follow the instructions carefully, you could win money which would be paid in cash at the end of the experience.

ECU (experimental currency unit) is the currency used during the experience, and all conversions will be made in ECU. At the end of the session, your profit will be paid in euros at the rate of $1 \mathrm{ECU}=0.1$ euro.

You will participate in the experience for 5 times of two periods each. Prior to the first period, the participants are divided randomly into groups of 2 . Therefore, there are 10 groups of two participants each. Within each group, each participant will be identified by a letter A or B. The decisions to be made by each participant during the two periods are detailed in the remaining instructions. At the end of the first period, the $B$ s are redistributed randomly within the groups while the As are not. At the end of the second period, the roles will be reassigned randomly and both periods are played 5 times.

The first period contains three steps carried out as follows.

Step 1. A receives 10 ECUs. A has the possibility of sending part of this amount to $B$, namely $p_{1}$, the amount sent to $B$ from $A$. At the end of this first step, A has $10-p_{1}$ ECU and B has $p_{1}$ ECU.

Example 3. If A sends 3 to B, A gets $7(10-3)$ and B gets 3.

Step 2. This step is the same as the previous step.

Step 3. This step is the same as the previous step.

The second period has two steps carried out as follows.

Step 1. C does not participate in this step. A receives 10 ECUs. $\mathrm{C}$ has the possibility of sending part of this amount to $\mathrm{B}$, namely $p_{1}$, the amount sent to B from A. B can accept or refuse this share. If $B$ refuses, $A$ and $B$ gain nothing. If $B$ accepts, A has $10-p_{1}$ ECU and B has $p_{1}$ ECU.

Example 4. If A sends 2 ECUs to $\mathrm{B}$ and if $\mathrm{B}$ refuses, $\mathrm{A}$ and $\mathrm{B}$ get nothing. If $B$ accepts, $A$ gets $8(10-2)$ and $B$ gets 2 . 
Step 2. This step is the same as the previous step.

Step 3. This step is the same as the previous step.

In the following:

(i) $p_{i}$ is the proposition made by $\mathrm{A}$ at step $i$

(ii) $p_{2} p_{1}=p_{2}-p_{1}$ (more generally $\left.p_{n} p_{(n-i)}=p_{n}-p_{(n-i)}\right)$

(iii) SDG and SUG are, respectively, the sanctions in the DG and UG.

\section{B. Descriptive Statistics}

Treatment 1 . See Table 9.

Control Treatment. See Table 10.

\section{Correlations Matrices}

First Experiments. See Table 11.

Control Treatment. Table 12.

\section{Percentages of Changes of the Propositions}

Treatment 1. See Table 13.

Control Treatment. See Table 14.

\section{E. Significance of the Differences between the Propositions}

Treatment 1. See Figure 1.

Control Treatment. See Figure 2.

Summary

(i) The DGs. See Table 15.

(ii) The UGs. See Table 16.

\section{F. Regressions of the Last Propositions $\left(p_{3}\right.$ (in the DG) and $p_{6}$ (in the UG)) on the Previous Propositions (resp. $p_{2}$ and $p_{5}$ ) and the Sanctions, in the UG (SUG) and the DG (SDG)}

See Table 17.

\section{G. Regressions of the Differences on the Differences}

(i) In the DGs. See Table 18.

(ii) In the UGs. See Table 19.

\section{References}

[1] E. Fehr and U. Fischbacher, "Third-party punishment and social norms," Evolution and Human Behavior, vol. 25, no. 2, pp. 63-87, 2004.
[2] W. Güth and R. Tietz, "Ultimatum bargaining behavior. A survey and comparison of experimental results," Journal of Economic Psychology, vol. 11, no. 3, pp. 417-449, 1990.

[3] C. Camerer, G. F. Loewenstein, and M. Rabin, Eds., Advances in Behavioral Economics, Princeton University Press, Princeton, NJ, USA, 2003.

[4] E. Fehr and S. Gächter, "Cooperation and punishment in public goods experiments," American Economic Review, vol. 90, no. 4, pp. 980-994, 2000.

[5] D. Masclet and M. C. Villeval, "Punishment, inequality, and welfare: a public good experiment," Social Choice and Welfare, vol. 31, no. 3, pp. 475-502, 2008.

[6] C. J. Turillo, R. Folger, J. J. Lavelle, E. E. Umphress, and J. O. Gee, "Is virtue its own reward? Self-sacrificial decisions for thesake of fairness," Organizational Behavior and Human Decision Processes, vol. 89, no. 1, pp. 839-865, 2002.

[7] E. Fehr and S. Gächter, "Altruistic punishment in humans," Nature, vol. 415, no. 10, pp. 137-140, 2002.

[8] J. P. Carpenter and P. H. Matthews, "Norm enforcement: the role of third parties," Journal of Institutional and Theoretical Economics, vol. 166, no. 2, pp. 239-258, 2010.

[9] E. Fehr and K. M. Schmidt, "Fairness, incentives, and contractual choices," European Economic Review, vol. 44, no. 4-6, pp. 1057-1068, 2000.

[10] E. Fehr and S. Gächter, "Do incentive contracts undermine voluntary cooperation?” Working Paper, University of Zurich, 2002.

[11] E. Fehr and J. A. List, "The hidden costs and returns of incentives-trust and trustworthiness among CEOs," Journal of the European Economic Association, vol. 2, no. 5, pp. 743-771, 2004.

[12] S. D. Levitt and J. A. List, "What do laboratory experiments measuring social preferences reveal about the real world?" Journal of Economic Perspectives, vol. 21, no. 2, pp. 153-174, 2007.

[13] A. K. Koch and H. T. Normann, "Giving in dictator games: regard for others or regard by others?" Southern Economic Journal, vol. 75, no. 1, pp. 223-231, 2005.

[14] E. Hoffman, K. McCabe, K. Shachat, and V. Smith, "Preferences, property rights, and anonymity in bargaining games," Games and Economic Behavior, vol. 7, no. 3, pp. 346-380, 1994.

[15] J. Dana, D. M. Cain, and R. M. Dawes, "What you don't know won't hurt me: costly (but quiet) exit in dictator games," Organizational Behavior and Human Decision Processes, vol. 100, no. 2, pp. 193-201, 2006.

[16] J. Andreoni and B. D. Bernheim, "Social image and the 5050 norm: a theoretical and experimental analysis of audience effects," Econometrica, vol. 77, no. 5, pp. 1607-1636, 2009.

[17] G. E. Bolton and R. Zwick, "Anonymity versus punishment in ultimatum bargaining," Games and Economic Behavior, vol. 10, no. 1, pp. 95-121, 1995.

[18] G. E. Bolton, K. Zwick, and E. Katok, "Dictator game giving: rules of fairness versus acts of kindness," International Journal of Game Theory, vol. 27, no. 2, pp. 269-299, 1998.

[19] I. Bohnet and B. S. Frey, "Social distance and other-regarding behavior in dictator games: comment," American Economic Review, vol. 89, no. 1, pp. 335-339, 1999.

[20] I. Bohnet and B. S. Frey, "The sound of silence in prisoner's dilemma and dictator games," Journal of Economic Behavior and Organization, vol. 38, no. 1, pp. 43-57, 1999.

[21] N. Frohlich, J. Oppenheimer, and J. Moore, "Some doubts about measuring self-interest using dictator experiments: the costs 
of anonymity," Journal of Economic Behavior and Organization, vol. 46, no. 3, pp. 271-290, 2001.

[22] T. C. Burnham, "Engineering altruism: a theoretical and experimental investigation of anonymity and gift giving," Journal of Economic Behavior and Organization, vol. 50, no. 1, pp. 133-144, 2003.

[23] K. J. Haley and D. M. T. Fessler, "Nobody's watching? Subtle cues affect generosity an anonymous economic game," Evolution and Human Behavior, vol. 26, no. 3, pp. 245-256, 2005.

[24] E. Hoffman, K. McCabe, and V. L. Smith, "Social distance and other-regarding behavior in dictator games," American Economic Review, vol. 86, no. 3, pp. 653-660, 1996.

[25] G. S. Berns, J. Chappelow, C. F. Zink, G. Pagnoni, M. E. Martin-Skurski, and J. Richards, "Neurobiological correlates of social conformity and independence during mental rotation," Biological Psychiatry, vol. 58, no. 3, pp. 245-253, 2005.

[26] M. F. Mason, R. Dyer, and M. I. Norton, "Neural mechanisms of social influence," Organizational Behavior and Human Decision Processes, vol. 110, no. 2, pp. 152-159, 2009.

[27] T. Ellingsen and M. Johannesson, "Anticipated verbal feedback induces altruistic behavior," Evolution and Human Behavior, vol. 29, no. 2, pp. 100-105, 2008.

[28] E. Xiao and D. Houser, "Emotion expression in human punishment behavior," Proceedings of the National Academy of Sciences of the United States of America, vol. 102, no. 20, pp. 7398-7401, 2005.

[29] E. Xiao and D. Houser, "Emotion expression and fairness in economic exchange," Working Paper, Interdisciplinary Center for Economic Science (ICES), George Mason University, 2007.

[30] E. Mohlin and M. Johannesson, "Communication: content or relationship?" Journal of Economic Behavior and Organization, vol. 65, no. 3-4, pp. 409-419, 2008.

[31] J. Andreoni and J. M. Rao, "The power of asking: how communication affects selfishness, empathy, and altruism," Journal of Public Economics, vol. 95, no. 7-8, pp. 513-520, 2011.

[32] S. Ferriol, “Regate-ng software," 2011, http://regate-ng.gate.cnrs .fr/ sferriol/debian/.

[33] R. Bénabou and J. Tirole, "Incentives and prosocial behavior," American Economic Review, vol. 96, no. 5, pp. 1652-1678, 2006.

[34] E. Fehr and U. Fischbacher, "The economics of strong reciprocity," in Moral Sentiments and Material Interests, The Foundations of Cooperation in Economic Life, H. Gintis, S. Bowles, and E. Fehr, Eds., MIT Press, Cambridge, UK, 2005. 


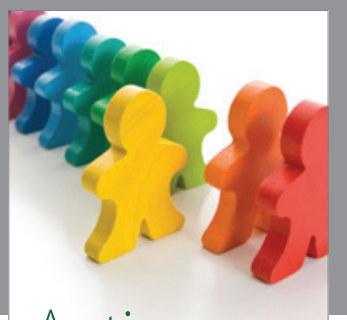

Autism

Research and Treatment
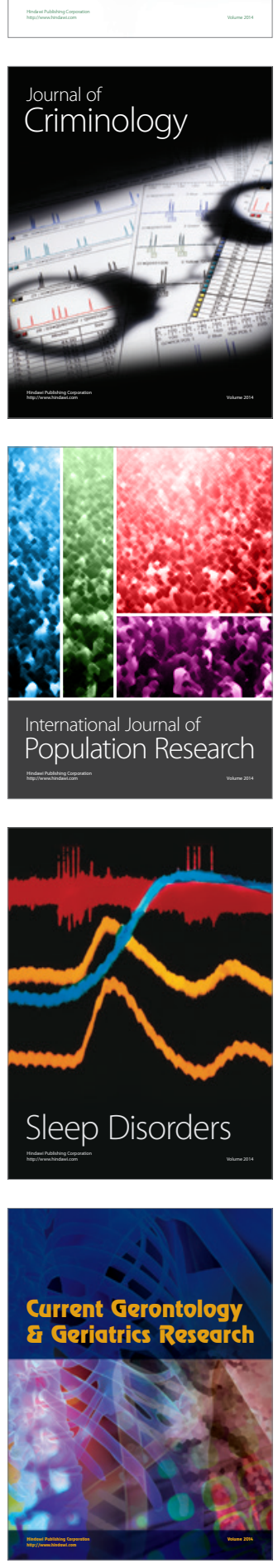
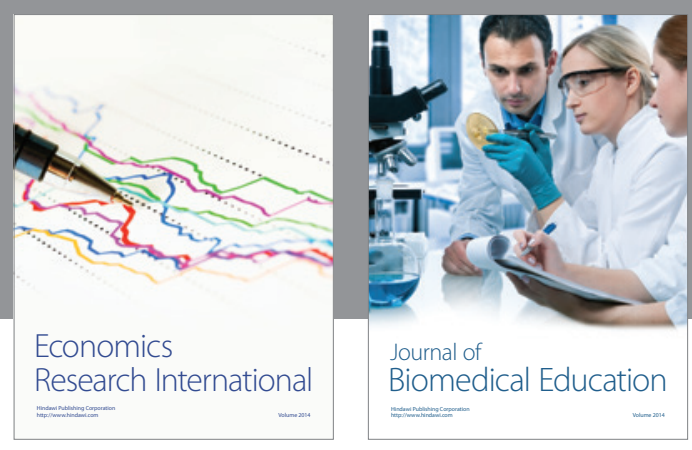

Journal of

Biomedical Education

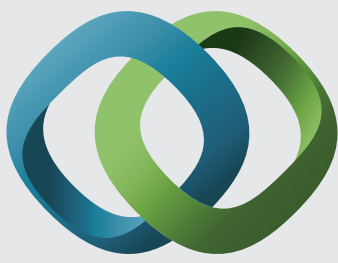

\section{Hindawi}

Submit your manuscripts at

http://www.hindawi.com
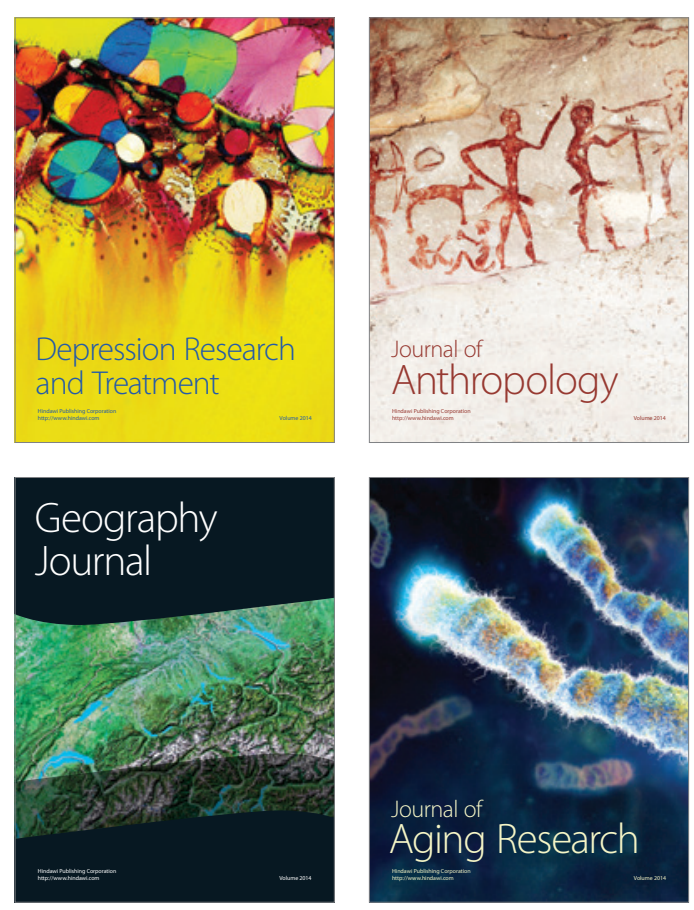

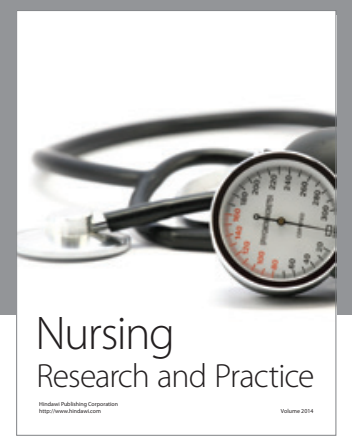

Nursing

Research and Practice

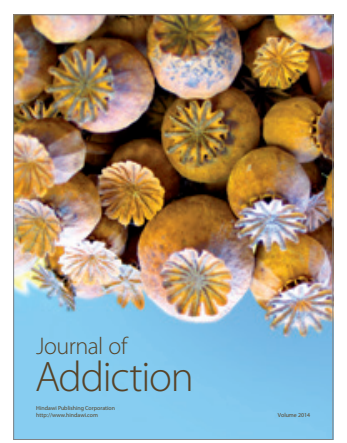

Child Development

Research

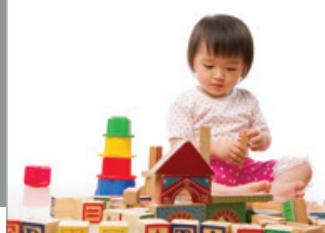

迥
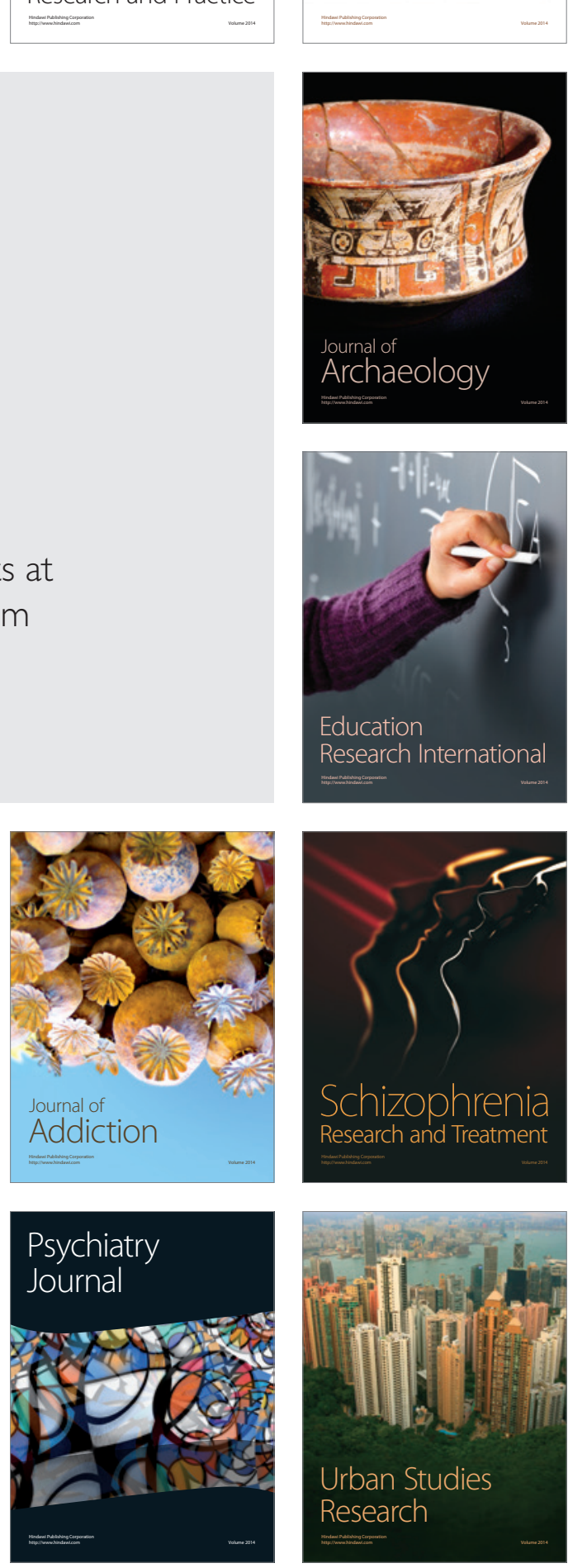